\title{
Construyendo un marco de evaluación de la atención primaria de la salud para Latinoamérica
}

\author{
Natalia Yavich, M en SP,(1) Ernesto Pablo Báscolo, M en Econ de la Sal y Serv de Sal, M en SP,(2) \\ Jeannie Haggerty, MSc, PhD. (3)
}

\author{
Yavich N, Báscolo EP, Haggerty J. \\ Construyendo un marco de evaluación \\ de la atención primaria de la salud para Latinoamérica. \\ Salud Publica Mex 20 10;52:39-45.
}

\begin{abstract}
Resumen
Objetivo. Determinar la claridad, relevancia y pertinencia de una estrategia de evaluación de la atención primaria de la salud en distintos subsistemas de salud. Material y métodos. La estrategia fue evaluada mediante talleres con tomadores de decisiones y responsables de la gestión de los servicios de tres organizaciones de salud, cada una de ellas de uno de los siguientes subtemas: subsistema pública, seguridad social y privado. El estudio fue realizado entre mayo de 2006 y mayo de 2007 en la Provincia de Santa Fe (Argentina). Resultados. La estrategia fue considerada clara y relevante de manera unámine, aunque sólo altamente pertinente por la organización pública. El seguro social y la aseguradora privada cuestionaron la pertinencia de evaluar el desarrollo de las acciones intersectoriales, la participación comunitaria y de considerar como parte del marco de evaluación a los determinantes de la salud.Asimismo consideraron necesario restringir a sus contribuyentes el alcance de las nociones de acceso universal y equidad en salud. Discusión. La valoración de la pertinencia de la estrategia fue explicada como resultado de las particularidades del contexto institucional, así como de las metas y estrategias de supervivencia desplegadas por cada organización.
\end{abstract}

Palabras clave: mecanismos de evaluación de la atención de salud; evaluación de programas e instrumentos de investigación; atención primaria de salud;América Latina; sistemas de salud
Yavich N, Báscolo EP, Haggerty J.

Building a primary health care evaluation

framework for Latin America.

Salud Publica Mex 20 10;52:39-45.

\begin{abstract}
Objective. To determinate the clarity, relevance and pertinence of a primary health care evaluation strategy for different Latin American health sub-systems. Material and Methods. This strategy was assessed using workshops held with decision makers and administrative managers from a public health organization, a social insurance and a private insurance health organization. The study took place in the province of Santa Fe (Argentina) between May 2006 and May 2007. Results. The strategy was determined to be clear and relevant by all organizations, but highly applicable only in the public case.The social-insurance and private cases questioned the pertinence of objectives related to community participation, intersectoral actions and a focus on social determinants of health, in addition to considering it necessary to restrict the scope of ideas related to universal access and equity with regard to their client population. Discussion. The evaluation of the pertinence of the strategy was explained by the particularities of the institutional context, as well as the goals and survival strategies used by each organization.
\end{abstract}

Key words: health care evaluation mechanisms; evaluation of research programs and tools; primary health care; Latin America; health systems

(I) Investiga MAS. Estudios de Salud y Sociedad. Buenos Aires, Argentina

(2) Departamento de Economía y Gestión en Salud. Instituto de la Salud Juan Lazarte. Provincia de Santa Fe, Argentina.

(3) Canada Research Chair on Population Impacts of Health Services. Université de Sherbrooke Canada. Québec, Canadá.

(4) Centre de recherche de l'Hospital Charles LeMoyne. Québec, Canadá. 
$\mathrm{E}^{\mathrm{n}}$ 2005, el Ministerio de Salud de Canadá elaboró una Estrategia de Evaluación de la Renovación de la Atención Primaria de la Salud (APS) ${ }^{1,2}$ Con vistas al desarrollo de un marco de evaluación útil para determinar y comparar el desempeño de la APS en Latinoamérica, en 2006 se analizó la relevancia y pertinencia de la aplicación de dicha estrategia en escenarios latinoamericanos. ${ }^{3}$ En este contexto, expertos comprometidos con el desarrollo de la APS en Latinoamérica reformularon la estrategia de evaluación canadiense. Debido a que ésta fue desarrollada a la medida de un sistema único y público, frente a la existencia de sistemas de salud segmentados los expertos tendieron a adecuar la estrategia para su aplicación en subsistemas públicos. No obstante, expresaron la necesidad de contar con marcos de evaluación capaces de ser aplicados al sistema en su conjunto, aún en el caso de sistemas segmentados.

\section{Material y métodos}

Entre mayo de 2006 y mayo de 2007 se condujo en Argentina un estudio orientado a evaluar la claridad, relevancia y pertinencia de la Estrategia de Evaluación Reformulada para Latinoamérica con el objetivo de explorar su valoración de la estrategia en organizaciones de distintos subsistemas de salud y reconocer los factores que explican tal valoración.

Es reconocido el hecho de que los marcos de evaluación se construyen a partir de criterios explícitos e implícitos derivados de observaciones empíricas y/o normas construidas a partir de consensos o experiencias previas. ${ }^{4}$ Por lo tanto, su valoración estará sujeta a la aceptación de tales criterios por parte de terceros. Ésta estará determinada a su vez por la capacidad de tales criterios de captar aspectos críticos del funcionamiento de la organización en cuestión.

Parsons ${ }^{5}$ identifica cuatro funciones esenciales de una organización de salud: el establecimiento de fines colectivos y la búsqueda de su consecución; la interacción con su entorno para obtener los recursos necesarios para su funcionamiento (adaptación al medio); la integración de procesos internos (normas y pautas de acción) para asegurar la productividad, y la construcción de instituciones orientadas a mantener la cultura, normas y valores que guían las tres funciones precedentes.

En vista de lo anterior, para comprender la valoración de la estrategia por parte de las organizaciones consultadas, éstas son descritas considerando la orientación de sus iniciativas de APS, los retos de cada una para lograr tales metas, las estrategias desarrolladas para enfrentar tales desafíos (adaptación al medio) y el modo de gobierno y normas de trabajo de los proveedores del primer nivel de atención (construcción de institucionalidad y normas de funcionamiento). Las descripciones fueron elaboradas a partir de revisiones de documentos y entrevistas con gerentes y tomadores de decisiones vinculados con el desarrollo de las estrategias de APS. Las descripciones resultantes fueron validadas en talleres con decisores y gestores de cada organización.

La valoración de la claridad, relevancia y pertinencia de la visión, misión y objetivos de la estrategia (cuadros I al III) se obtuvo como resultado de talleres desarrollados con la participación de tomadores de decisiones y responsables de la gestión y del sistema de información de los servicios de primer nivel de atención de cada organización. La claridad fue definida como la comprensión y utilización de los enunciados sin mediar necesidad de presentar aclaraciones sobre su sentido o sobre el significado de alguno de los términos incluidos en los enunciados. Para valorar la claridad se invitó a los participantes a manifestar sus dudas respecto de los enunciados que considerasen de difícil comprensión. Asimismo se identificaron conceptos que en el marco de la discusión hubiesen sido utilizados por distintos participantes con significados diferentes. La relevancia de los enunciados se determinó a partir de su adecuación para evaluar aspectos prioritarios y/o críticos de la APS. La pertinencia se consideró como la adecuación de los enunciados para evaluar aspectos prioritarios de las iniciativas de APS de las organizaciones bajo estudio. Los participantes priorizaron los objetivos y fueron invitados a modificar los enunciados para tornarlos más pertinentes en el marco de su organización.

La investigación "Indicator development for tracking the expansion of primary health care", en la cual se enmarca este trabajo, fue aprobada por el Comité de Ética de la Universidad de Sherbrooke (Canadá). ${ }^{3}$

\section{Resultados}

\section{La organización del subsistema público}

La organización del subsistema público es una secretaría de salud pública municipal que dirige y coordina una red de servicios propia conformada por efectores de primer, segundo y tercer nivel de atención destinada a brindar atención a alrededor de 350000 personas sin cobertura de salud. La mayor parte de los centros de salud cuenta con un equipo integrado por médicos de las especialidades básicas (generalistas y/o pediatras, clínicos y tocoginecólogos y/u obstetras), enfermeros, administrativos y profesionales de salud de otras especialidades médicas y no médicas.

La conducción de los centros de salud es responsabilidad de la dirección de APS. En espacios de gestión 
colegiada la dirección de APS y los equipos de los centros de salud se reúnen para discutir los problemas y las estrategias de acción de la organización. La secretaría orienta la acción de los centros de salud a través de la promoción de un conjunto de principios orientadores: equidad y universalidad en el acceso, participación, resolutividad clínica y responsabilización. Bajo este marco cada centro tiene libertad para definir su propia modalidad de trabajo.

Las principales dificultades que enfrenta la estrategia de APS de la secretaría se relacionan con: la contención de una creciente demanda de servicios, la coordinación de los distintos niveles de atención y la captación de aquella población que por sus condiciones socioeconómicas y/o características culturales experimentan mayores barreras de acceso a los servicios.

Las estrategias utilizadas para el logro de sus objetivos son: el desarrollo de mecanismos de gestión participativa (dirigidos hacia los trabajadores y la comunidad), la consolidación de equipos de salud multidisciplinarios con fuerte vocación comunitaria y el fomento de la responsabilización de los equipos sobre su población. La APS en este escenario es considerada como una estrategia de organización del sistema de salud tendiente hacia el logro de la equidad en el acceso, la participación comunitaria, la programación local de los servicios y la democratización del sistema de salud y la sociedad.

\section{La organización del subsistema de la seguridad social}

La organización de la seguridad social es una delegación de una "obra social sindical nacional" que brinda cobertura a cerca de 1110000 afiliados. La delegación es regida por un director general designado por la gestión central del cual dependen un gerente médico y un gerente administrativo. En la gestión del primer nivel de atención participa en forma directa una consultora contratada por el nivel central que regula y monitorea los procesos de trabajo y la modalidad de atención del primer nivel de atención. Esto implica una limitación del nivel de autonomía de los equipos de salud. El segundo y tercer nivel de atención están conformados por hospitales privados contratados bajo la modalidad de pago capitado o por prestación.

Los principales desafíos que ha enfrentado la organización en los últimos 15 años están vinculados con la necesidad de controlar los costos y mejorar las condiciones de accesibilidad de la población afiliada, la calidad técnica, la coordinación de acciones con otros niveles de atención, la capacidad resolutiva del primer nivel y la gama de servicios ofrecidos. La estrategia para hacer frente a estos desafíos ha sido la creación de un primer nivel de atención propio y la expansión de la gama de servicios, con miras a fortalecer la atención preventiva y el grado de resolutividad del primer nivel, así como mejorar la coordinación de la atención entre los diferentes niveles.

En este marco se crean los centros de salud ambulatorios, a través de los cuales se brindan servicios médicos (medicina familiar, pediatría, clínica, ginecología, tocoginecología, traumatología, dermatología, cardiología y oftalmología) y otros servicios de salud (enfermería, psicología, odontología, fonoaudiología, kinesiología). Desde estos puntos se toman muestras para estudios de laboratorio y se gestionan las solicitudes de internación, interconsultas y otras prácticas.

La APS en este escenario es considerada como una estrategia del primer nivel de atención a través de la cual es posible articular niveles de atención mediante un modelo de medicina familiar orientado a resolver y prevenir problemas de salud entre los afiliados.

\section{La organización del subsistema privado}

La aseguradora privada forma parte de un holding de empresas perteneciente a una asociación médica municipal, que brinda cobertura a 10000 personas. La administración de la aseguradora está a cargo de un comité de gestión, conformado por un gerente general, un gerente médico y un gerente contable. El mismo es designado y conducido por el directorio de la asociación médica.

La oferta de servicios de primer nivel de atención se estructura mediante acuerdos de pago por servicios con profesionales independientes (principalmente médicos) y centros de diagnóstico. Las principales especialidades médicas ofrecidas son: clínica, pediatría, cardiología y endocrinología. Recientemente se incorporaron psicólogos a la oferta de servicios básicos.

El nivel de autonomía de los profesionales del primer nivel es sumamente alto. Los mismos cuentan con total libertad para definir sus horarios y días de atención, la ubicación de sus consultorios, su modalidad de entrega de turnos y modelo de atención.

El principal reto de la aseguradora es equilibrar la tensión entre la necesidad de aumentar la cobertura para satisfacer y retener a un perfil de clientes que tiende a demandar servicios especializados y tecnología de última generación y la exigencia de contener los costos del sistema para lograr una ganancia económica. Esta dificultad se inscribe en un contexto de alta fragmentación de la atención entre los diferentes prestadores.

Una estrategia para enfrentar estos retos ha sido la implementación de nuevos planes competitivos, econó- 
micamente accesibles y "regulados", es decir, basados en una nómina limitada de profesionales del primer nivel de atención, responsables de conducir el acceso a prácticas y consultas en el segundo y tercer nivel de atención.

En este escenario la APS es considerada como un modelo de atención implementado mediante el desarrollo de planes competitivos que garanticen la contención de costos y la resolución de problemas de salud. Para ello se incorpora la figura de médicos responsables de conducir el proceso de atención de los afiliados a los fines de lograr una utilización de servicios costoefectiva y brindar una atención accesible, aceptable y de alta calidad técnica.

\section{Valoración de la estrategia}

\section{Claridad}

Ninguno de los participantes experimentó dificultades para comprender el sentido de los enunciados. Sin embargo, el significado que se le dio a las nociones de población, comunidad, proveedores de APS y planificación local varió como resultante de las diversas características que presentan en cada organización. El seguro social y la aseguradora privada utilizaron el término "población" para referirse a sus "afiliados" o "clientes" en forma nominal, mientras que la organización pública mantuvo el sentido de "población" como colectivo social y geográficamente delimitado. La organización pública utilizó el término "proveedores de APS" para referirse a equipos de salud multidisciplinarios, mientras que el seguro social y la aseguradora privada lo utilizaron para hacer referencia a los profesionales médicos individualmente. La "planificación local" fue concebida por la organización pública como programación de actividades por parte de cada centro de salud. La aseguradora privada la conceptualizó como la planificación de acciones por parte de sus proveedores, considerando sus respectivos pacientes. El seguro social visualizó la planificación local como una actividad propia de cada delegación destinada a definir la modalidad de organización, la conformación de los equipos de salud y el establecimiento de acuerdos con terceros prestadores.

\section{Relevancia y pertinencia}

La visión (cuadro I) fue considerada relevante y pertinente por los representantes de la organización pública, en tanto expresaba su propia visión. Para los representantes del seguro social y la aseguradora privada la visión fue considerada relevante en términos teóricos, pero no consideraron que expresara su visión operativa.

El seguro social y la aseguradora privada delimitaron el alcance de las nociones de acceso universal, equidad en salud o determinantes sociales a sus afiliados/ clientes, en tanto que su preocupación se centra en sus contribuyentes.

Si bien el sindicato que alberga el seguro social brinda servicios sociales a los afiliados, la intersectorialidad no constituye un desafío prioritario de la organización. La influencia sobre los determinantes de la salud tampoco es considerada como parte de su visión. Tales dimensiones tampoco son visualizadas como parte de la visión de la aseguradora privada.

Para ambas organizaciones el crecimiento de la cantidad de afiliados, la contención de costos y la ampliación de la gama de servicios ofrecidos constituyen fuertes preocupaciones, que no son explícitamente abordadas por la estrategia.

\section{Misión y objetivos}

La misión encontró un considerable nivel de aceptación en los tres escenarios. No obstante, se propusieron cambios para mejorar su pertinencia en cada organización (cuadro II). Los cambios introducidos por la organiza-

\section{Cuadro I \\ ReleVANCIA Y PERTINenCIA DE LA VISIÓN DE APS de LA Estrategia DE EVALUACIÓN REFormulada PARA LATINOAMÉRICA}

Visión
Organización pública

Seguro social

Aseguradora privada

La APS constituye una estrategia a través de la cual es posible influir sobre los determinantes de la salud, trabajar intersectorialmente, coordinar las acciones entre los distintos niveles del sistema y garantizar la participación comunitaria con la finalidad de contribuir a la equidad en salud y al acceso universal a servicios de calidad
Relevante y per- Relevante, pero no Relevante, pero no tinente pertinente pertinente

Fuente: La visión propuesta por los expertos constituye una adaptación de la visión de la APS explicitada en OPS/OMS, 20076 
ción pública ampliaron su alcance, pero no modificaron su sentido. Se objetó que los equipos de APS deban ser "idealmente multidisciplinarios", ya que se considera a la multidisciplinariedad como una condición básica. Se rechazó que la responsabilización de los equipos de APS deba limitarse a los problemas "comunes" de salud, ya que se considera que los equipos deben responsabilizarse (aunque no necesariamente asistir clínicamente) por todos los problemas de salud de su población. Todos los objetivos fueron considerados relevantes y pertinentes, siendo los de acceso universal y participación comunitaria identificados como aquellos de mayor prioridad y el de acceso de primer contacto y trabajo intersectorial como los menos prioritarios (cuadro III).

El seguro social consideró que la misión propuesta era compatible con la propia, aunque no altamente sensible para captar sus prioridades. Se consideró necesario reemplazar el concepto de "comunidad" por el de "afiliados y su grupo familiar" y se señaló la baja pertinencia de las nociones de participación comunitaria e intersectorialidad (cuadro II). Todos los objetivos fueron considerados relevantes. Los objetivos de participación comunitaria e intersectorialidad no fueron considerados pertinentes. El resto de los objetivos fue considerado pertinente, pero se señaló la necesidad de restringirlos a sus afiliados y sus servicios. Los objetivos de acceso de primer contacto y coordinación de servicios resultaron ser los menos prioritarios. Los objetivos más prioritarios fueron los de planificación local y acceso universal, entendido éste como el propósito de brindar acceso universal y equitativo a sus afiliados.

La aseguradora privada consideró a la misión relevante, pero poco pertinente para su organización. Los cambios introducidos para aumentar su pertinencia consistieron en el reemplazo de los términos "comunidad" por "clientes" y "equipo de APS, idealmente multidisciplinario" por "profesional médico del primer nivel de atención". La mención a la participación comunitaria, la intersectorialidad y la planificación local fueron excluidas de la misión.

Todos los objetivos fueron considerados relevantes y pertinentes, a excepción de los objetivos de participación comunitaria y trabajo intersectorial los cuales fueron, considerados relevantes pero no pertinentes. Para aumentar la pertinencia de la estrategia, el seguro social y la aseguradora privada señalaron la necesidad de restringir el alcance de los enunciados a sus respectivos servicios y afiliados/clientes. Asimismo, se advirtió la necesidad de incorporar un nuevo objetivo vinculado a la contención de costos. Los objetivos priorizados fueron los de calidad técnica y aceptabilidad de la atención. Los objetivos de planificación local y acceso universal resultaron ser los menos prioritarios.

\section{Discusión}

La estrategia resultó clara y relevante en las tres organizaciones. Sin embargo, su pertinencia sólo fue alta

\section{Cuadro II}

\section{Reformulación* de La misión de APS de la Estrategia de EValuación Reformulada para Latinoamérica}

\begin{abstract}
Dentro del sector salud el primer nivel de atención tiene un rol principal -pero no exclusivo- de brindar servicios de atención primaria en las comunidades. El equipo de APS, multidisciplinario, garantiza la atención de primer contacto; presta atención integral, integrada y apropiada con responsabilidad principal de manejar problemas de salud, brindar prevención y promoción de la salud, coordinar cuidados con otros niveles de atención, promover la participación comunitaria y coordinar con otros sectores que tienen influencia sobre los determinantes de la salud. Las familias y comunidades son su base para la planificación y acción.
\end{abstract}

Dentro del sector salud el primer nivel de atención tiene un rol principal -pero no exclusivo- de brindar servicios de atención primaria a sus afiliados y grupo familiar en las comunidades. El equipo de APS, idealmente multidisciplinario, garantiza la atención de primer contacto; presta atención integral, integrada y apropiada con responsabilidad principal de manejar problemas comunes de salud, brindar prevención y promoción de la salud; y coordinar cuidados con otros niveles de atención,promover la participación comunitaria y coordinar con otros sectores que tienen influencia sobre los determinantes de la salud. Las familias y comunidades son su base para la planificación y acción.

Dentro del sector salud el primer nivel de atención tiene un rol principal -pero no exclusivo- de brindar servicios de atención primaria a sus clientes en las comunidades. El profesional médico del primer nivel de atención El equipo de APS, idealmente untediseiplinario, garantiza la atención de primer contacto; presta atención integral, integrada y apropiada con responsabilidad principal de manejar problemas comunes de salud, brindar prevención y promoción de la salud; $y$ coordinar cuidados con otros niveles de atención, promover la participación comunitaria y coordinar con otros sectores que tienen influencia sobre los determinantes de la salud. Las familias y comunidades son su base para la planificación y acción.

\footnotetext{
* Las reformulaciones se indican en formato subrayado para el texto agregado y las supresiones con el texto en formato tachado
} 


\section{Cuadro III \\ Pertinencia y PRiorización* de los objetivos de la APS, por escenario}

\begin{tabular}{|c|c|c|c|}
\hline Objetivos & $\begin{array}{l}\text { Organización } \\
\text { pública }\end{array}$ & Seguro social & $\begin{array}{l}\text { Aseguradora } \\
\text { privada }\end{array}$ \\
\hline $\begin{array}{l}\text { Acceso universal. Garantizar el acceso universal y equitativo de la población a una atención integral e integrada } \\
\text { basada en una relación continua y personalizada con los proveedores de APS. }\end{array}$ & Sí (+) & Sí $(+)^{\ddagger}$ & Sí $(-)^{\ddagger}$ \\
\hline $\begin{array}{l}\text { Calidad técnica. Brindar servicios seguros y de alta calidad y promover una cultura de calidad en las institu- } \\
\text { ciones y proveedores de APS. }\end{array}$ & Sí & Sí & Sí (+) \\
\hline $\begin{array}{l}\text { Aceptabilidad de servicios. Asegurar por parte de los trabajadores de salud habilidades eficaces de comuni- } \\
\text { cación, respeto por la autonomía de la persona y un trato digno y aceptable para los usuarios de acuerdo a } \\
\text { su contexto sociocultural y personal. }\end{array}$ & Sí & Sí & Sí (+) \\
\hline $\begin{array}{l}\text { Acceso de primer contacto. Asegurar el acceso de primer contacto a la población incluyendo los servicios } \\
\text { de urgencia las } 24 \text { horas al día y la efectiva referencia a los proveedores de APS asignados. }\end{array}$ & Sí (-) & Sí (-) & Sí \\
\hline $\begin{array}{l}\text { Atención integral e integrada. Garantizar la atención integral (salud física y mental, episodios agudos, cuidados } \\
\text { crónicos, paliativos y de rehabilitación, actividades de promoción y prevención) e integrada a los individuos } \\
\text { y a la población asignada a un equipo de APS. }\end{array}$ & Sí & $\mathrm{Si}^{\prime \dagger}$ & $\mathrm{Si}^{\prime \neq}$ \\
\hline $\begin{array}{l}\text { Coordinación de servicios. Facilitar la coordinación entre las instituciones, los profesionales y los trabajadores } \\
\text { que proveen servicios de salud en diferentes puntos de atención, para evitar la fragmentación y lograr una } \\
\text { atención integrada. }\end{array}$ & Sí & Sí $(-)^{\S}$ & $\mathrm{Si}^{\S}$ \\
\hline $\begin{array}{l}\text { Planificación local de servicios. Planificar la oferta local de servicios necesarios dentro de la estrategia de APS } \\
\text { para responder a las necesidades de la salud de una población definida. }\end{array}$ & Sí & Sí (+) & Sí (-) \\
\hline $\begin{array}{l}\text { Participación comunitaria. Promover un enfoque comunitario y participativo de la atención y la gestión de } \\
\text { los servicios. }\end{array}$ & Sí (+) & No & No \\
\hline $\begin{array}{l}\text { Trabajo intersectorial. Promover y desarrollar acciones intersectoriales para la intervención en los determi- } \\
\text { nantes que afectan la salud. }\end{array}$ & Sí (-) & No & No \\
\hline
\end{tabular}

* La priorización fue medida en términos de los dos objetivos más prioritarios (+) y los dos objetivos menos prioritarios (-) en el marco de cada organización. Sólo los objetivos relevantes fueron considerados como elegibles para ser priorizados

¥ Pertinente tomando como referencia a la población asegurada

$\S$ Pertinente considerando a los servicios incluidos en la red de servicios de la organización

para la organización pública. La comprensión de la APS como estrategia del sistema implicó por parte de la organización pública una identificación con la visión propuesta. En cambio las concepciones de APS como primer nivel de atención ${ }^{6}$ por parte del seguro social y la aseguradora privada supusieron una baja pertinencia de los componentes vinculados a la promoción de la participación comunitaria, el trabajo intersectorial y los determinantes de la salud.

La modalidad de financiamiento de cada organización (contribuciones provenientes de impuestos generales o aportes de afiliados/clientes) provocó que las concepciones de "población objetivo" fueran diversas y, en el caso de la aseguradora privada y el seguro social, contrastantes con la planteada por la estrategia. Este aspecto limitó la pertinencia del componente de acceso universal y equitativo, en la medida en que las organizaciones de la seguridad social y la privada sólo promueven el acceso entre sus contribuyentes. La ausencia de un objetivo que aborde el desafío de captar afiliados / clientes -sólo contemplado a través del objetivo de aceptabilidad de la atención- fue considerada como una debilidad de la estrategia.
La conformación de la red de servicios (integrada, contratada o mixta) y la capacidad de regular el comportamiento de los proveedores del primer nivel de atención (orientación a través de principios y mecanismos de gestión participativa, regulación mediante normas o términos de contratación) afectaron la valoración de la pertinencia de los objetivos de coordinación de servicios y acceso de primer contacto. En la organización pública, la coordinación de servicios se reconoce como un desafío prioritario y se desarrollan acciones tendientes a alcanzarlo. En cambio, el seguro social y la aseguradora privada enfrentan mayores limitaciones para el desarrollo de mecanismos de coordinación debido a su restringida capacidad de regulación sobre los servicios contratados.

La adecuación de la noción de proveedores de APS se vio afectada por las características de los proveedores de servicios de primer nivel de atención en cada escenario. Mientras que la organización pública y el seguro social compartían la conceptualización de proveedores de APS de la estrategia, la aseguradora privada concebía a los proveedores de APS como profesionales no integrados en equipos. 
La contratación del primer nivel de atención por parte de la aseguradora privada afectó la pertinencia del objetivo de planificación local y acceso de primer contacto, en tanto la organización carece de capacidad para limitar la autonomía de los proveedores. En el seguro social, la planificación local es una actividad realizada por cada delegación. A la inversa, en la organización pública se promueve la planificación local a nivel de los equipos de salud. De este modo, la planificación adquiere una fuerte pertinencia en ambos escenarios, pero con distintos sentidos, finalidades y responsables.

En los tres escenarios la estrategia fue considerada clara y relevante. Sin embargo, su pertinencia fue cuestionada por las organizaciones de la seguridad social y privada. Las diferencias en la valoración se explicaron por los rasgos constitutivos de cada organización, delineados por las respectivas metas, estrategias de supervivencia y contexto institucional (perfilado por las características de los subsistemas de salud que contienen a cada organización).

\section{Implicaciones de la valoración de la estrategia}

Numerosas propuestas han sido elaboradas para evaluar el desempeño de las iniciativas de APS promovidas e implementadas al interior del subsistema público de salud. ${ }^{7-9}$ Las mismas se han concentrado en la evaluación del desempeño de los servicios de primer nivel de atención y/o de diversos programas orientados a fortalecer la APS. En contraste, los esfuerzos tendientes a formular herramientas de evaluación de sistemas de salud desde una perspectiva macro han sido escasos. ${ }^{10}$ La Estrategia de Evaluación Reformulada para Latinoamérica se inscribe en este último conjunto de enfoques que buscan trascender la evaluación de servicios o programas para comprender y captar el desempeño del sistema de salud como un todo, no obstante sus rasgos de segmentación o integración.

Los criterios subyacentes en la estrategia tienen fuertes puntos de contacto con el enfoque de APS integral, descrito por la OPS. ${ }^{6}$ Los resultados de este estudio, lejos de afirmar la falta de relevancia de los principios de la APS integral en los subsistemas privado y de la seguridad social, demuestran que la valoración de la pertinencia de la estrategia estuvo fuertemente influenciada por el grado de identificación de tales organizaciones con los principios de la APS integral. Por último, se observó que la identificación de las organizaciones con el enfoque de APS como puerta de entrada ${ }^{6}$ y la baja valoración de la intersectorialidad y la participación comunitaria son condicionantes y productos de las metas de las organizaciones, su estructura y sus estrategias de supervivencia y reproducción.

\section{Agradecimientos}

Los autores agradecen el apoyo de los Canadian Institutes of Health Research y la colaboración de las autoridades y profesionales de las organizaciones comprometidas en el estudio.

\section{Referencias}

I. Haggerty J, Martin CM. Evaluating Primary health care in Canada:The right questions to ask! Ottawa: Health Canada, 2005.

2. Canadian Institute for Health Information $(\mathrm{ClHI})$. Measuring the future of Primary health care in Canada. Canada: Canadian Institute for Health Information (ClHI), 2006.

3. Haggerty JL, Yavich N, Báscolo EP. Grupo de Consenso sobre un Marco de Evaluación de la Atención Primaria en América Latina. Un marco de evaluación de la atención primaria de la salud en América Latina. Rev Panam Salud Publica 2009;25(5):377-384.

4. Champagne F, Contandriopoulos AP, Pineault R.A health care evaluation framework. Health Manage Forum 1986;7(2):57-65.

5. Parsons T. Social systems and the evolution of action theory. New York: Free Press, 1977.

6. Organización Panamericana de la Salud / Organización Mundial de la Salud (OPS/OMS). La renovación de la atención primaria de salud en las Américas. Washington DC: Organización Panamericana de la Salud / Organización Mundial de la Salud (OPS/OMS), 2007.

7.Almeida C, Macinko J.Validaçao de uma metodologia de avaliaçao rápida das características organizacionais e do desempenho dos serviços de atençao básica do Sistema Único de Saúde (SUS) em nível local. Brasilia: Organización Panamericana de la Salud / Organización Mundial de la Salud (OPS/OMS), 2006.

8. Sala A, Nemes M, Cohen D. Metodología de avaliaçao do trabalho na atençao primária à saúde. Cad Saude Publica 1998; I4(4):741-75।.

9. Atkinson S, Haran D. Individual and district scale determinants of users' satisfaction with primary health care in developing countries. Soc Sci Med 2005;60:50I-5I3.

10. World Health Organization. Now more than ever - The World Health Report 2008. Switzerland:World Health Organization, 2008. 